\title{
O DISCURSO DO AGRONEGÓCIO E DA AGRICULTURA FAMILIAR E O CARÁTER EXCLUDENTE DAS POLÍTICAS AGRÁRIAS
}

\author{
Thiago Henrique Costa Silva ${ }^{1}$ \\ Maria Izabel de Melo Oliveira dos Santos ${ }^{2}$
}

\begin{abstract}
RESUMO
Este artigo analisará as políticas agrárias brasileiras, buscando compreender quais premissas que as fundamentam. Através do materialismo histórico dialético, instrumentalizado pela análise do discurso, discute-se as ideologias que permeiam o agronegócio, relacionando-as com as políticas públicas rurais. Observa-se como o discurso do agronegócio se coloca frente à agricultura familiar. Evidencia-se que tal discurso hegemônico importa na defesa do latifúndio, da monocultura, tendo a produtividade como elemento central. Assim, a agricultura familiar seria um construto jurídico para a transposição do camponês, supostamente atrasado, para uma categoria moderna, capaz de se integrar às premissas do agronegócio, sendo essa a finalidade fundamental das políticas agrárias.
\end{abstract}

PALAVRAS-ChAVE: Análise do discurso; Políticas Agrárias; Agronegócio; Agricultura familiar; Camponês.

\section{THE DISCOURSE OF AGRIBUSINESS AND FAMILY AGRICULTURE AND THE EXCLUDENT CHARACTER OF AGRARIAN POLICIES}

\begin{abstract}
This article will analyze the Brazilian agrarian policies, trying to understand which assumptions are based on them. Through dialectical historical materialism, instrumented by discourse analysis, we discuss the ideologies that permeate agribusiness, relating them to rural public policies. It is observed how the discourse of agribusiness confronts family agriculture. It is evidenced that such hegemonic discourse matters in the defense of the large property, of the monoculture, having the productivity like central element. Thus, family farming would be a juridical construct for the transposition of the supposedly backward peasantry into a modern category capable of integrating itself with the premises of agribusiness, which is the fundamental purpose of agrarian policies.
\end{abstract}

KEYWORDS: Speech analysis; Agrarian Policies; Agribusiness; Family farming; Peasant farmer.

\footnotetext{
1 Perito criminal. Professor de Direito Constitucional do Centro Universitário Alves Faria (UNIALFA). Doutorando em Agronegócio pela Universidade Federal de Goiás (PPAGRO). Mestre em Direito Agrário pela Universidade Federal de Goiás (PPGDA). E-mail: thiagocostasilva.jur@gmail.com.

${ }^{2}$ Advogada. Coordenadora do Curso de Direito e Professora de Direito Civil do Centro Universitário Alves Faria (UNIALFA). Mestre em Direito Agrário pela Universidade Federal de Goiás (PPGDA). E-mail: izabel@marsuraemelo.adv.br.
} 


\section{INTRODUÇÃO}

O discurso dos diversos atores sociais que circundam o agronegócio traz à tona uma série de jogos de verdades, a partir da ressignificação dos conceitos que norteiam as políticas agrárias $^{3}$, utilizando-os como meios de propagações ideológicas. Nesse jogo de interesses, a agricultura familiar é compreendida como uma categoria forjada politicamente, com o intuito de modernizar os atrasados camponeses, além de inseri-los na lógica produtivista (NEVES, 2007), tornando-os competitivos para o mercado (CARNEIRO, 1997).

Nesse sentido, o objetivo deste trabalho é analisar os acontecimentos e movimentos discursivos que permeiam a formulação das políticas públicas para o rural brasileiro, considerando o lugar de construção das diferentes falas para delinear um lugar comum de representações ideológicas. De maneira específica, buscar-se-á: discutir a busca pela homogeneização do campo brasileiro e de seus sujeitos; compreender os conceitos e histórico do agronegócio e agricultura familiar; identificar os principais argumentos discursivos do agronegócio; e analisar as políticas agrárias e sua conexão com esse discurso.

Como método de pesquisa, adotou-se o materialismo histórico dialético, na perspectiva da análise do discurso (CAREGNATO; MUTTI, 2006), com o fim de interpretar a realidade agrária e sua dinâmica. Como metodologia, as pesquisas bibliográfica e documental, realizadas com o fim de trazer os argumentos do discurso do agronegócio, servirão de base para a compreensão do tema e para o acúmulo teórico necessário para discuti-lo.

Para tanto, considera-se que o discurso vai além da fala e da escrita, correspondendo a uma representação ideológica, decorrente de um acúmulo social e histórico (ROMÃO; PACÍFICO, 2008). Com base nas ideias de Althusser e de Foucault, a análise do discurso visa compreender a realidade oculta dos argumentos, levando em conta o inconsciente dos sujeitos que os exprimem, de maneira a desvelar as obviedades (CHARRADEAU; MEINGENEAU, 2008; FOUCAULT, 2008).

$\mathrm{Na}$ busca de avaliar se realmente existe um discurso que parte dos agentes do agronegócio e se tal discurso influencia a formulação de políticas públicas, partir-se-á da ideia de que o agronegócio encontra fundamento na concentração fundiária e no modelo produtivista de monocultura para exportação, englobando, nas duas últimas décadas, a

\footnotetext{
3 Não há um uso despretensioso ou equivocado do termo "agrário" neste artigo. Ao contrário, busca-se evidenciar que as políticas públicas para o campo brasileiro vão (ou pretendem ir) além da questão econômica e agrícola, atreladas à produção e ao crescimento econômico, perpassando, portanto, as questões ambientais, sociais, culturais, fundiárias, de segurança alimentar, de saúde pública, dentre tantas outras.
} 


\section{O DISCURSO DO AGRONEGÓCIO E DA AGRICULTURA FAMILIAR E O CARÁTER EXCLUDENTE DAS POLÍTICAS AGRÁRIAS}

agricultura familiar como parte de suas engrenagens de funcionamento. Dessa forma, em uma interpretação crítica, a agricultura familiar passa a ser uma espécie de "agronegociozinho", reduzindo, de maneira simplista, as diversidades camponesas, como forma de neutralizar a polaridade social (NEVES, 1995).

Em seguida, busca-se demonstrar que várias políticas públicas para o campo brasileiro, sobretudo as fundiárias e de créditos, incluindo aquelas pensadas para a agricultura familiar, sofrem influência pelo discurso hegemônico do agronegócio, exercido em uma relação de poder, construída no decorrer da história brasileira sobre sólidas bases econômicas e políticas (SILVA, 2016).

Logo, verifica-se que as políticas públicas excluem sob o argumento de incluir, desconsiderando os diferentes modos de vida e de produção ao impor uma lógica mercadológica e produtivista como elemento central para sua efetivação. Esse discurso acaba por desconstruir os saberes tradicionais e locais, impondo uma agenda econômica sobre agendas ambientais e sociais.

A terra e o homem passam a ser apenas mais um elemento do grande negócio moderno, mecanizado e produtivo. Dessa forma, nem mesmo a nomenclatura "políticas agrárias" faz sentido, ao passo que o Estado, impelido pelo discurso dominante, assume a função de formular e fomentar as políticas agrícolas e de comercialização, fomentando a concentração de terras e de renda, ampliando a desigualdade social e regional, em uma reprodução das mazelas liberais.

\section{1 do CAMPESinAto AO Agronegócio: A PROPOSTA DA AgRiCUlTuRA FAMILIAR}

A despeito das políticas neoliberais para o campo e do avanço do agronegócio, o modo de vida camponês, com resiliência, perpassa a história brasileira representando um conjunto de significações do coletivo e de comunidade local (ALMEIDA, 1998), "cujos eixos são constituídos pelos laços familiares e de vizinhança" (WANDERLEY, 2014, p. 31).

A relação desse sujeito do campo com a terra é parte de uma ideologia, "que juntamente com a produção de alimentos, produz categorias sociais, pois o processo de trabalho além de ser um encadeamento de ações técnicas, é também um encadeamento de ações simbólicas, ou seja, um processo ritual” (WOORTMANN e WOORTMANN, 1997, p. 15). 
O campesinato é marcado pela centralidade do patrimônio familiar e por um específico sistema de produção (sistema de policultura-pecuária), que visa o atendimento das necessidades da família e sua reprodução pelas próximas gerações, podendo os sujeitos que a compõe exercerem uma pluriatividade, até mesmo através de trabalhos externos (WANDERLEY, 1996).

Os camponeses se organizam em um sistema estruturado nas relações sociais/familiares e em um saber fazer em relação a terra e aos animais, em que os cultivos são escolhidos de acordo com a sazonalidade e com as condições familiares, sendo cultivados por atos de produção complexos e específicos, ordenados por uma sabedoria popular local (WOORTMANN e WOORTMANN, 1997).

\footnotetext{
Numa perspectiva geral, o campesinato corresponde a uma forma social de produção, cujos fundamentos se encontram no caráter familiar, tanto dos objetivos da atividade produtiva - voltados para as necessidades da família - quanto do modo de organização do trabalho, que supõe a cooperação entre os seus membros. A ele corresponde, portanto, uma forma de viver e de trabalhar no campo que, mais do que uma simples forma de produzir, corresponde a um modo de vida e a uma cultura (WANDERLEY, 2014, p. 26).
}

Pode-se afirmar que as relações dos grupos familiares não se baseiam em um sistema contratual, mas sim na confiança, nos vínculos criados ao longo da vida, em relações de caráter personalizados (MENDRAS, 1978), com um conjunto de regras próprias, criando um sistema de regulação interno (WOLF, 1970), vivendo em uma sociedade mais solidária, coletiva, construída a partir de seus modos de vida (SHANIN, 1971), de economias parciais, fundadas em inserções sociais a mercados incompletos (ELLIS, 1988).

Já os setores do agronegócio, enquanto detentores da tecnologia de produção, seriam os entes facilitadores da produção ao comércio interno e externo, proporcionando o funcionamento da engrenagem industrial e comercial. Os seus entusiastas utilizam os números para demonstrar que a balança comercial brasileira teria sérios problemas se não fosse o desenvolvimento dessa área comercial (CEPEA; CNA, 2016).

O agronegócio tem seu conceito baseado no termo agrobusiness, que é delineado na Universidade Harvard, por Davis e Goldberg, em meados dos anos 1960. Parte-se do argumento de que, no atual mundo globalizado, existe uma grande dependência entre todos os elementos que constituem o mercado produtor, como fornecedores, produtores de matériaprima e consultoria. Considerando essa relação de dependência, o conceito de agronegócio superaria a divisão tradicional de indústria, serviços e agricultura e incorpora todas as 


\section{O DISCURSO DO AGRONEGÓCIO E DA AGRICULTURA FAMILIAR E O CARÁTER EXCLUDENTE DAS POLÍTICAS AGRÁRIAS}

empresas que de algum modo produzem, processam e distribuem produtos que possuem origem agropecuária.

Baseado nesses conceitos, há entendimento no sentido de que a agricultura familiar é parte do agronegócio, pois seria um agronegócio diversificado, com uma cadeia mais curta, e destinado ao mercado local. A grande diferença residiria na extensão da cadeia e na flexibilidade do sistema para atender às necessidades do "pequeno produtor" (CEPEA; CNA, 2016).

Fazendo uma análise econômica, segundo dados do IBGE e CEPEA/USP, o agronegócio representa aproximadamente $23 \%$ do Produto Interno Bruto brasileiro, com a verificação de sua incidência, preponderantemente na região Sudeste (CEPEA; CNA, 2016). E é nessa fala que se funda a afirmação de Abramovay e Veiga (1998) ao assegurar que o agronegócio no Brasil é um lugar de pujança e desenvolvimento, não constituindo apenas uma atividade de grandes produtores, vez que consegue englobar a agricultura familiar.

A agricultura familiar, nesse sentido, deveria se nortear por quatro elementos fundamentais: 1) proximidade do modelo de processo produtivo e de administração de negócio, muitas vezes criados para a própria subsistência familiar; 2) ausência de cadeia formal e sistematizada na constituição do processo produtivo; 3) foco direcionado à agregação de valor da mercadoria e diversificação produtiva de matérias-primas; 4) práticas de produção sustentável e de consumo em pequena escala de matérias-primas (GASSON et al, 1993, p. 18).

Corroborando, Veiga (2004) entende a agricultura familiar como algo apto a se modernizar, não devendo ser atrelada a um caráter "“rudimentar', sem competitividade, comparável à dos fazendeiros, os únicos inseridos em agronegócios." Para ele é preciso inferir que "em toda parte o agribusiness é composto por um conjunto heterogêneo de cadeias produtivas, cujos elos primários contam com inúmeros tipos de agricultores e pecuaristas, majoritariamente de caráter familiar".

Veiga (2004) acredita que a ideia de contraposição entre agricultura familiar e agronegócio é na verdade uma "bobagem", institucionalizada por aqueles que não desejam que a agricultura familiar alcance o seu desenvolvimento. Nesse sentido, "o assentado deve ser cobrado a produzir", inserindo-se ao agribusiness, que conta com ampla participação da agricultura familiar (ABRAMOVAY; VEIGA, 1998). Dessa forma, os autores reforçam a ideia produtivista que permeia o agronegócio. 
[...] obstáculo teórico para a compreensão da realidade agrária contemporânea no capitalismo central está nas ambiguidades com que a noção de unidade familiar de produção tem sido tratada. Convém insistir neste ponto, pois a associação entre esse tipo de estabelecimento e small farm, "pequena produção", "produção de baixa renda", 'agricultura camponesa", entre outros, é recorrente e impede que se perceba a dupla e fundamental especificidade da agricultura familiar tal como se desenvolveu, sobretudo após a Segunda Guerra Mundial, nos países capitalistas avançados: por um lado, seu dinamismo econômico, sua capacidade de inovação técnica, suas formas sociais inéditas com relação ao passado de que algumas vezes se origina, mas com o qual mantém laços cada vez mais tênues. Por outro lado - e este é um aspecto decisivo - a agricultura familiar é um fenômeno tão generalizado nos países capitalistas avançados que não pode ser explicada pela herança histórica camponesa, de fato, em alguns casos existente: na verdade, o Estado foi determinante na moldagem da atual estrutura social do capitalismo agrário das nações centrais. (ABRAMOVAY, 1998, p. 21).

Na visão de Veiga e Abramoway (1998), o agronegócio é um conceito oriundo de uma ideologia baseada no mercado europeu, neologismo do conceito clássico de agribusiness, cujo corpo teórico é de origem positivista, fundado na cultura da inclusão e desenvolvimento no campo.

Nessa análise de convivência pacífica, é possível destacar a agricultura familiar ocupando papel importante na política de segurança alimentar, gerando o mercado interno de alimentos e matérias-primas, bem como por oferecendo contribuições para a sustentabilidade e equidade de inclusão social.

Surgindo no Brasil na década de 90, através de um projeto político nacional supostamente inclusivo, com inspiração no Family Farming europeu (CARNEIRO, 1997, p.71), a nomenclatura agricultura familiar, que, na teoria estatal, traria consigo elementos de modernidade, integraria os agricultores aos anseios da sociedade (WANDERLEY, 1996, p. $1)$.

Para tanto, Ricardo Abramovay (1992), através de uma análise quantitativa, destacou a realidade norte americana, inglesa e da comunidade europeia, demonstrando a centralidade da agricultura familiar e importância desta para o desenvolvimento do capitalismo. Segundo o autor, além de serem o maior número de estabelecimentos agrícolas nos países ditos desenvolvidos, os estabelecimentos familiares se destacavam na produção e na oferta diversificada de alimentos.

Sendo assim, a agricultura familiar encontraria seu espaço, enquanto o campesinato desapareceria, auxiliando o capitalismo a se desenvolver e encontrar estabilidade social, com um mercado consumidor consolidado, contudo a atividade agrícola, por suas particularidades, não sofreria um processo de industrialização típico do capitalismo (ABRAMOVAY, 1992. p. 246). 


\title{
O DISCURSO DO AGRONEGÓCIO E DA AGRICULTURA FAMILIAR E O CARÁTER EXCLUDENTE DAS POLÍTICAS AGRÁRIAS
}

Em sua tese de doutoramento, que deu origem a obra "paradigmas do capitalismo agrário", Ricardo Abramovay (1992) propagava os fundamentos que permeariam as políticas públicas para a agricultura não patronal nas próximas décadas:

\begin{abstract}
a) a defesa de que, com a expansão do capitalismo no campo, o campesinato tende a metamorfosear-se em pequeno capitalista do campo; b) a agricultura familiar destaca-se pelo caráter moderno das atividades produtivas enquanto o campesinato permanece como a expressão do atraso; c) defende a integração da produção ao mercado como formas modernas de desenvolvimento no campo e uma maior especialização da produção (RAMOS FILHO, 2008, p. 363).
\end{abstract}

Ocorre que a visualização do campesinato integrado à lógica mercadológica invisibiliza os conflitos e a dimensão histórica dos termos, especialmente ao substituí-los por outros termos vazios de significados (WANDERLEY, 1996; RAMOS FILHO, 2008, p. 363; WANDERLEY, 2014, p. 30).

Entretanto a adoção do conceito não foi pacífica entre os movimentos sociais e os órgãos agrários, sendo que no interior do Movimento Sindical dos Trabalhadores Rurais (MSTR), por exemplo, houve uma disputa teórica e ideológica que culminou na criação do Movimento dos pequenos produtores (MPA), que buscariam se inserir nos programas governamentais (SAUER, 2008, p. 21).

Essa nova denominação, que incluiu grupos tão diversos utilizadores de trabalho familiar, aliadas a outras categorias com modos de vida próprios - extrativistas, silvicultores, pescadores, quilombolas, indígenas e ribeirinhos -, é passível de críticas, uma vez que foi forjada pelo Estado para estabelecer uma política pública esquizofrênica, econômica para alguns e social para outros (NEVES, 2007, p. 15 e 16), constituindo, por isso, uma categoria jurídica, mas não de fato. Por isso, o agrupamento em uma única categoria, a agricultura familiar, que teria acontecido para atender uma demanda política de representatividade, alinhada ao discurso e desenvolvimento de políticas facilitadoras da modernização e do produtivismo, só poderia ser compreendido no sentido socioeconômico para o qual foi criado (NEVES, 2007, p. 18).

Infere-se então que, a relação homem-terra, em função do surgimento de estruturas fragmentadas, passa a ser visto como sistema de processos múltiplos, simultâneos e interativos, envolvendo diferentes atores e fluxos em diversas direções. Por outro lado, a crescente especialização de áreas produtivas em diferentes ramos, bem como a maior institucionalização práticas discursivas e recursivas que os caracteriza, impõe uma necessidade de determinar a extensão e os limites dos impactos intersistêmicos de ambos os 
sistemas parcialmente autônomos $(\mathrm{KOH}, 2016$, p. 8), neste trabalho representados pela agricultura familiar ${ }^{4}$ e agronegócio.

Assim, dadas as particularidades produtivas de cada ambiente econômico autônomo, a ausência de consenso sobreposto nas relações intersistêmicas e a presença de dissenso estrutural entre as ordens normativas parciais de agronegócio e camponeses são postas como condições de possibilidade da própria existência de tais sistemas.

Infere-se, portanto, que, sob a égide de se incrementar as relações de igualdade no processo produtivo e unificar relações historicamente heterárquicas, cria-se um discurso de poder de convivência pacífica das relações discursivas entre camponeses e agronegócio, em que pese seus distintos objetivos e mecanismos de constituição produtiva, proporcionando-se o fenômeno de disdiferenciação sistêmica entre ordens normativas parcialmente autônomas do sistema social da economia de agricultura, o que impede, inclusive, a projeção de circularidade intersistêmica de aprendizado mútuo entre ambos os sistemas de agricultura.

Contudo, uma vez estabelecida por processos de diferenciação sistêmica, tal relação intersistêmica proporciona a confluência entre ambos os processos produtivos, isto é, ocasiona a solução e absorção de dissonâncias sociais, ao mesmo tempo em que as relações camponesas sofrem influência pelas relações dos empresários do agronegócio - e vice-versa em relação paradoxal de complementariedade, mediante transversalidade reflexiva e tensões recíprocas de ambos os sistemas, gerando uma dupla legitimação: democrático-política e jurídica.

Nesse sentido, esta racionalidade deve atuar como ponte de transição (NEVES, 2016, p. 55), com a auto-observação recíproca sobre temas paralelamente enfrentados $(\mathrm{KOH}, 2016$, p. 6), a exemplo do modelo produtivo e dos caminhos para a comercialização dos produtos agropecuários.

A tendência de conversação institucional por meio de heterarquias entrelaçadas, suavizaria resultados conflitantes, provenientes da análise de um mesmo assunto por pontos de vista distintos, o que impacta substancialmente no processo de fragmentação, de forma a tornar o sistema mais coerente, pela interação, entre ambos, buscando a interconexão dos regimes produtivos, que produzem racionalidades distintas, mas representativas de valores que procuram se afirmar internamente (PETERS, 2016, p. 12).

\footnotetext{
${ }^{4}$ Importa falar que o termo agricultura familiar está sendo utilizado em consonância com as legislações brasileiras, contudo o termo camponês é o mais adequado para compreender a dialética existente entre as diferentes propostas de modelo produtivo: a do agronegócio, baseada na comoditização, aumento da produtividade e crescimento econômico; e a do campesinato, relacionada aos modos de vida, à interação homemnatureza, importando em discutir, para além do viés econômico, a questão ambiental e a questão agrária.
} 
Portanto, a partir da divergência como condição de possibilidade da convergência de diferenciação de ambos os regimes produtivos em múltiplos níveis, o estabelecimento de heterarquias entrelaçadas tem o potencial de preservar a unidade do sistema (PETERS, 2016, p. 10) agropecuário, com um efeito integrador, em que a diferenciação e autonomização sistêmica demonstram que, na atual arquitetura nacional, a discussão estabelecida internamento é insuficiente, emergindo-se novas perspectivas de relações entre ambos os sujeitos. Todavia, enquanto tal processo se desenvolve, não há um caminho a ser seguido pelas políticas públicas (ou, quando existe, está enviesado), em virtude da ausência de estratégia de desenvolvimento rural (FAVARETO, 2010).

\section{O DISCURSO DO AGRONEGóCIO E A FORMULAÇÃo DE POLÍticAS PÚBLICAS}

É possível notar que há uma contraposição de discursos no campo brasileiro: de um lado o discurso do campesinato e de outro o discurso do agronegócio. Enquanto o discurso do agronegócio se pauta na busca pelo aumento de produtividade com vistas à exportação, o campesinato se apresenta como parte que conserva o modo de vida, voltando-se à localidade e às práticas agroecológicas.

No que tange à elaboração das políticas agrárias, todavia, nota-se que sua formulação se coloca alinhada aos propósitos estabelecidos como desejáveis pelo discurso adotado pelo agronegócio. Mesmo as políticas direcionadas à agricultura familiar visam o enquadramento de pequenos agricultores no padrão agroexportador e pouco diversificado.

O Programa Nacional de Fortalecimento da Agricultura familiar (PRONAF) tem como objetivo geral a consolidação da capacidade produtiva de agricultores familiares, ampliando sua capacidade de investimento por meio da concessão de crédito para realização de projetos que são avaliados conforme as potencialidades do produtor e da região onde ele se encontra. $\mathrm{O}$ foco é a contribuição para o emprego e renda nas áreas rurais bem como melhorias na qualidade de vida (SCHNEIDER, CAZZELLA, MATTEI, 2004).

Criado em 1996, o PRONAF se presta a concessão de financiamentos para realização de investimentos ou o custeio da produção. Existem linhas específicas para mulheres, indígenas jovens, pescadores, quilombolas e pode abranger atividades rurais não agrícolas como industrialização familiar, turismo rural e agrocombustíveis (CORCIOLI; CAMARGO, 2016). 
O programa seguiu o mesmo modelo aplicável para os produtores que se pautam em negócio enquadrado nas técnicas da revolução verde, com alto uso de mecanização, baseado em monoculturas de commodities direcionadas à exportação. Todavia, serviu como resposta às pressões por políticas agrárias para superação de dificuldades de agricultores familiares (SCHNEIDER, CAZZELLA, MATTEI, 2004).

Em larga medida, pode-se afirmar que o PRONAF foi formulado como resposta do Estado às pressões do movimento sindical rural, realizadas desde o final da década de 1980. O programa nasceu com a finalidade de prover crédito agrícola e apoio institucional aos pequenos produtores rurais que vinham sendo alijados das políticas públicas até então existentes e encontravam sérias dificuldades de se manter no campo (SCHNEIDER, CAZZELLA, MATTEI, 2004, p. 2).

Obviamente, nem todos os agricultores familiares foram ou serão contemplados pelo crédito concedido por meio do PRONAF. Mesmo porque a concessão de créditos levanta desconfianças entre os agricultores camponeses. Aqueles que possuem estrutura mais alinhada a mercados dinâmicos e estão integrados a cadeias produtivas ligadas à agroindústria tendem a acessar os recursos do PRONAF com maior facilidade e regularidade (QUEIROZ, LUNAS, FRIAS, 2015, p.13).

Avaliando a quantidade de agricultores que tiveram acesso ao crédito do PRONAF e os valores disponibilizados, percebe-se o aumento nos montantes e a estabilização da quantidade de agricultores que recebem o financiamento. Isto permite a conclusão de que os mesmos indivíduos recebem o crédito oriundo do PRONAF ano após ano e o programa não apresenta a capilaridade que dele se esperava (CORCIOLI, CAMARGO, 2016)

No decorrer dos anos, evidenciou-se que o Pronaf e as políticas públicas decorrentes, destinadas aos agricultores familiares, não alcança a totalidade desse grupo tão amplo, sobretudo no que tange a política de créditos, uma vez que apenas $18 \%$ conseguiam acessá-los no último censo agropecuário, em 2006 (BARROS, 2010, p. 254), predominantemente por estados da região sul, sendo utilizado, em sua maior parte, para a produção de monocultivos de grãos (AQUINO e SCHNEIDER, 2010, p. 335).

Na mesma linha de entendimento, Leomar Prezzoto (2005), afirma que, a despeito da grande quantidade de pequenas propriedades e de sujeitos classificados como agricultores familiares, a maioria das políticas públicas e legislações correlatas não são voltadas para a esse setor, ou, quando são, não alcançam a totalidade de realidades, marginalizando e excluindo grande parcela daqueles que exercem a atividade rural. 


\section{O DISCURSO DO AGRONEGÓCIO E DA AGRICULTURA FAMILIAR E O CARÁTER EXCLUDENTE DAS POLÍTICAS AGRÁRIAS}

Não obstante o valor disponibilizado pelo Plano Safra aumente a cada ano agrícola, o valor aplicado sempre ficou abaixo e o número de contratos realizados permanece inalterado, o que propicia a conclusão de que o número de beneficiários permanece o mesmo, aumentando apenas a concentração de recursos para uma parcela específica de produtores familiares (CORCIOLI, CAMARGO, 2016).

Em Goiás, por exemplo, verifica-se a tendência de aumento do recurso aplicável ao restante do país. No entanto, número de contratos permanece inalterado. O Plano Safra da Agricultura familiar de 2014 e 2015 estabelecia que o R\$ 522,5 milhões destinados à pecuária. Foram realizados 21 mil contratos. À agricultura coube o estabelecimento de cercade 2 mil contratos que negociaram R\$ 70 milhões, sendo quase 2 mil contratos (CORCIOLI, CAMARGO, 2016).

Em 2005, R\$ 173 milhões foram negociados em cerca de 29 mil contratos realizado no estado de Goiás. Em 2014, R \$ 588 milhões foram aplicados a 23 mil contratos, o que denota a concentração de recursos entre aqueles que já tinham acesso ao programa (CORCIOLI, CAMARGO, 2016).

Ao agronegócio é destinada política a mesma política de crédito rural estabelecida para o setor desde 1937. O crédito rural foi o grande financiador da modernização conservadora entre os anos de 1960-90. A partir de 1995, o Tesouro nacional passou a subsidiar os juros arcando com a diferença entre o valor do mercado e o valor pago pelos produtores. O crédito rural elimina as atualizações e adota taxas fixas de acordo com o programa realizado. Os valores são destinados ao custeio, investimento e comercialização (CORCIOLI; NUNES; CAMPOS, 2016).

Os valores e as taxas, bem como os programas existentes são avaliados a cada ano/safra por meio da publicação do Plano Agrícola e Pecuário (PAP). Os Fundos Constitucionais de financiamento são os responsáveis por prover os valores destinados ao setor produtivo para reduzir desigualdades regionais. São compostos por $3 \%$ do IPI e do Imposto de Renda. Ao Fundo constitucional do centro-oeste (FCO) toca receber $0,6 \%$ do IPI e IRPF.

O FCO é operado pelo Banco do Brasil e tem $44 \%$ de seu valor dedicado ao FCO rural, que tem taxas de juros mais baixas, financia até 100\% do investimento, tem carência de até 12 anos, bônus por adimplência e prazos de até 20 anos para pagamento (CORCIOLI; NUNES; CAMPOS, 2016). 
O PAP atende a médios e grandes produtores e se concentra em milho, soja, cana, arroz, café, carne e frango. O PAP 2015/2016 disponibilizou 187 bilhões para aplicação em custeio, investimento e comercialização (CORCIOLI; NUNES; CAMPOS, 2016).

O Programa de Agricultura de Baixo Carbono (ABC) é uma linha de crédito que incentiva atividades vinculadas a redução da emissão de gases de efeito estufa. Entre eles, a recuperação de pastagens, produção orgânica, sistemas agroflorestais, manejo de florestas, recomposição de Áreas de Preservação Permanente e Reservas Legais (CORCIOLI; NUNES; CAMPOS, 2016).

Desta forma, o camponês torna-se refém das estratégias das políticas de mercado do Estado, que de forma camuflam as políticas de desenvolvimento nacional voltadas para o mercado externo.

A estratégia do capital neoliberal, segundo Petras e Veltmeyr (2008), visa associar políticas em prol do crescimento com políticas sociais em prol do "desenvolvimento sustentável humano". Também desenvolve instituições de políticas de "boa governança", que direcionam a sociedade para serem os protagonistas, assumindo as funções do Estado assegurando o desenvolvimento local ou realizando pequenos projetos com o objetivo de diminuição da pobreza, através do acesso à terra pela sociedade assistida pelo mercado.

Neste contexto, verifica-se a inserção da agricultura familiar no discurso de desenvolvimento rural, fortalecimento do capitalismo agrário e expansão do agronegócio (OLIVEIRA JUNIOR, 2010, p.2). E neste mesmo contexto, o camponês e sua força de trabalho rural se torna uma ferramenta para a defesa deste desenvolvimento e expansão, enquanto políticas públicas de crédito (PRONAF) figuram como mais uma ferramenta de fortalecimento das oligarquias agrárias

É necessário ressaltar ainda que as políticas de desenvolvimento não protegem as comunidades tradicionais, que, muitas vezes, não possuem dados e informações para alcançalas. Além disso, conforme defende Conceição e Souza (2008), o discurso do agronegócio visa a sua expansão e o fortalecimento dos latifúndios, pois buscam propagar a ideia de que a grande maioria das terras possui potencialidade para a produção, e a apropriação de novos territórios é necessária para o verdadeiro desenvolvimento, reproduzindo a exploração histórica de muitas áreas daquelas comunidades.

Sob a dinâmica das extensas relações do capital que se sustentam pela via institucional do Estado, promove-se a expansão da política de crédito rural do PRONAF, enquanto mola-propulsora de uma estratégia que assenta as bases em um novo padrão de desenvolvimento capitalista no campo brasileiro, sem, contudo, 
modificar as velhas formas que caracterizam as Políticas Públicas para o campo, cuja racionalidade é manter o viés concentrador, setorial e produtivista que caracteriza o modelo de desenvolvimento agrícola no Brasil, em que o campo tornase cada vez mais território de controle e de poder de latifundiários e das indústrias na apropriação do trabalho e da natureza (RODRIGUES, 2016, p.11).

No governo popular dos governos Lula e Dilma, verificou-se a inserção de retomada de velhos discursos e promessas, mas sem abandonar o discurso de desenvolvimento, ou neodesenvolvimentista. As políticas implementadas mantiveram as propostas neoliberais e assimilaram o discurso das velhas políticas de reserva, ou seja, o processo de desenvolvimento é necessário para a expansão e acumulação de capital (MARANHÃO, 2014).

Essas políticas alimentaram as financeiras, que, através de seus financiamentos e projetos, provocaram o endividamento do produto, sem deixar de reconhecer que estes financiamento e programas de transferência monetária também tiveram efeitos positivos na melhoria imediata da situação econômica de muitas famílias rurais, que viviam em completa miséria (MARANHÃO, 2014).

O caráter contraditório das políticas públicas, que anunciadoras do desenvolvimento local baseada em financiamento do crédito tem direcionado a produção camponesa a produzir cultivos específicos inseridos na lógica do agronegócio, o que faz com que o camponês se especialize produzindo o que o PRONAF lhe disponibiliza em recursos, em detrimento, por exemplo, de um processo de diversificação da produção assentada no plantio dos cultivos voltados ao autoconsumo da produção camponesa (RODRIGUES, 2016, p.13).

Verifica-se, assim, que as políticas públicas e a inserção de créditos direcionados para a agricultura familiar, na verdade financia a tecnologia e o "projeto de modernização" do campo. Todo o maquinário e insumos agrícolas, provenientes da agroindústria e empresas transnacionais, além das sementes modificadas provenientes das indústrias de biotecnologia, e de outras imposições de mercado de consumo, direcionam o agricultor familiar para a subordinação e dependência de mercado, associando ao agronegócio e a política neoliberal.

Consequência desta ação verifica-se a mudança de culturas, aumento da monocultura, concentração de produção, e fortalecimento da agroindústria. Como consequência, o agricultor familiar aumenta suas dívidas para buscar o aumento da produção, direcionando sua produção para abastecimento do mercado de commodities. De tal modo, as políticas agrárias são formuladas desprezando os diferentes modos de vida e excluindo os camponeses do campo, mesmo tendo sido criadas, supostamente, para mantê-los nele. 


\section{CONSIDERAÇÕES FINAIS}

A análise das políticas agrárias brasileiras conduz à conclusão de que não existe no Brasil apontamentos específicos que considerem as peculiaridades da agricultura familiar. As mesmas estratégias de desenvolvimento rural pensadas para atender às demandas de produtores que pautam seus empreendimentos em imóveis rurais de grandes extensões, baseados em monoculturas direcionadas à exportação são replicadas para atender a agricultores camponeses, assentados da reforma agrária, indígenas e quilombolas.

A falta de atenção às peculiaridades da agricultura familiar e camponesa (ou a proposital desconsideração de sua diversidade) acaba por selecionar entre os agricultores familiares aqueles que mais se alinham ao modelo de desenvolvimento hegemônico característico do agronegócio.

As políticas agrárias supostamente direcionadas à agricultura familiar tem como fundo discurso típico do agronegócio, na medida em que incentivam a tomada de medidas voltadas homogeneizar as iniciativas de produtores, com o fim de que se estabeleçam em cadeias organizadas para integrar um grupo de pessoas (cooperativas e associações) com objetivos comuns. A realização da agricultura cooperativa, que funciona como perfeito mecanismo de relógio, é aplaudida pelas forças estatais e acaba por receber na forma de financiamento o incentivo para que se mantenha como réplica do agronegócio na produção de gêneros agroexportáveis.

Assim, pode-se concluir que a política agrária brasileira se sustenta sob o discurso que entende o desenvolvimento rural como a realização de culturas altamente utilizadoras dos pacotes tecnológicos da revolução verde, inundando o mercado externo com o produto da moda. Enquanto isso, o campesinato, que se afasta do paradigma de desenvolvimento mecanizado de commodities, é associado ao conceito de atraso e superação, razão pela qual é indigna de receber investimentos públicos. Afinal, consoante esse discurso, não há razão em investir em algo que não possui qualquer chance de sucesso.

Todavia, a despeito do abandono e da sabotagem estatal, a agricultura camponesa persiste e encontra novos caminhos para evitar seu desaparecimento com a adoção de práticas agroecológicas e o estabelecimento de redes de cooperação pautadas no resgate de práticas tradicionais integradas à natureza. Desse modo, é importante a realização de pesquisas que apontem os problemas e caminhos para a elaboração de políticas agrárias plurais e 


\section{O DISCURSO DO AGRONEGÓCIO E DA AGRICULTURA FAMILIAR E O CARÁTER EXCLUDENTE DAS POLÍTICAS AGRÁRIAS}

participativas, que consigam romper com a ideologia do produtivismo e crescimento econômico, incorporando as experiências intersistêmicas do campesinato e do agronegócio.

\section{REFERÊNCIAS}

ABRAMOVAY, R. Paradigmas do capitalismo agrário em questão. São Paulo, Rio de Janeiro, Campinas: Editora Hucitec, ANPOCS, Editora da UNICAMP, 1992.

ABRAMOVAY, R.; VEIGA, J. E. da. Novas Instituições para o desenvolvimento rural: o caso do Programa Nacional de Fortalecimento da Agricultura familiar (PRONAF). Brasília: IPEA, 1998.

ALMEIDA, J. A construção social de uma nova agricultura: tecnologia agrícola e movimentos sociais no sul do Brasil. Rio grande do Sul: Editora da Universidade Federal do Rio Grande do Sul, 1998.

AQUINO, J. R.; SCHNEIDER, S. 12 anos da política de crédito do PRONAF no Brasil (1996-2008): uma reflexão crítica. Revista de extensão e estudos rurais. v. 1, n. 2, p. 309-347, jul.-dez. 2011.

BARROS, G. S. C. Política agrícola no Brasil: subsídios e investimentos. In: GASQUES, J.G.; VIEIRA FILHO, J.E.R.; NAVARRO, Z. A agricultura brasileira: desempenho, desafios e perspectivas, IPEA, cap. 11, p. 237-258, 2010.

CARAGNATO, R. C. A; MUTTI R. Pesquisa qualitativa: análise de discurso versus análise de conteúdo. Revista Texto \& Contexto- Enfermagem. Florianópolis. out-dez 2006, p. 679684.

CARNEIRO, M. J. Política pública e agricultura familiar: uma leitura do Pronaf. Revista Estudos, Sociedade e Agricultura, abr. 1997.

CHARAUDEAU, P.; MAINGUENEAU, D.. Dicionário de análise do discurso. Trad. Fabiana Komesu. São Paulo: Contexto, 2008.

CEPEA; CNA. PIB do Agronegócio: Brasil. 2016 Disponível em: <https://www.cepea.esalq.usp.br/upload/kceditor/files/Relatorio\%20PIBAGRO\%20Brasil_N OVEMBRO.pdf>. Acesso em: 31 mar. 2018.

CONCEIÇÃO, A. L. SOUZA, S. T. As "novas" estratégias do capital para o campo brasileiro a partir do discurso do agronegócio. Revista Pegada, Vol. 9, No 1. 2008

CORCIOLI, G.; CAMARGO, R. Programa Nacional de Fortalecimento da Agricultura familiar (PRONAF). In: Agricultura familiar em Goiás: lições para o assessoramento técnico. Goiânia: UFG, 2016. 
CORCIOLI, G.; NUNES, C.; CAMPOS, L. Crédito rural. In: Agricultura familiar em Goiás: lições para o assessoramento técnico. Goiânia: UFG, 2016.

ELLIS, F. Household strategies and rural livelihood diversification. Journal of Development Studies, Londres, v. 35, n. 1, 1998, p. 1-38.

FAVARETO, A. As políticas de desenvolvimento territorial rural no Brasil em perspectiva uma década de experimentações. In: Boschi e outros (orgs). Desenvolvimento em debate, v.1, n.2, p.47-63. Rio de Janeiro: INCT, janeiro-abril e maio-agosto, 2010.

FOUCAULT, M. A arqueologia do saber. Forense, 2008.

GASSON, R. et al. The farm family business. Cab International, 1993.

KOH, H. H. Transnational Legal Process. Faculty Scholarship Series Paper, n. 2 096, 1996. Disponível em: <http:lldigitalcommons.law.yale.edu/fss_papers12096>. Acesso em: 18 jan. 2016.

MARANHÃO, C. A ideologia neodesenvolvimentista: crise do capital, novas estratégias e velhas promessas da classe dominante brasileira. In: MONTAÑO, C. O canto da sereia: crítica à ideologia e aos projetos do "terceiro setor". São Paulo: Cortez, 2014.

MENDRAS, H. Sociedades camponesas. São Paulo: Zahar. 1978.

NEVES, D. P. Agricultura familiar: Quantos ancoradouros! In: FERNANDES, Bernardo Mançano; MARQUES, Marta Inez Medeiros; SUZUKI, Julio Cesar (orgs.). Geografia Agrária: Teoria e Poder. - 1.ed. - São Paulo: Expressão Popular, 2007. p. 211-270.

NEVES, D. P. Agricultura familiar: questões metodológicas. Reforma Agrária - Revista da Associação Brasileira de Reforma Agrária, n. 2 e 3, v. 25, p. 21-36, 1995.

OLIVEIRA JÚNIOR, M. P de. Agroindústria e campesinato no centro-sul de Sergipe. In: anais do XVI Encontro Nacional de Geógrafos Crise, práxis e autonomia: espaços de resistência e de esperanças Espaço de Diálogos e Práticas. Porto Alegre, 2010.

PETERS, A. The Refinement of International Law: From Fragmentation to Regime Interaction and Politicization. 2016. Disponível em: <http://papers.ssrn.com/sol3/papers .cfm?abstract_id=2823512>. Acesso em: 8 set. 2016.

PETRAS, J.; VELTEMEYER, H. Capitalismo e Democracia: Conflito, compatibilidade e instrumentação. In: Hegemonia do Estados Unidos no novo milênio. Petrópolis, Vozes. 2000 .

PREZOTTO, L. L. A sustentabilidade da agricultura familiar: implicações e perspectivas da legislação sanitária para a pequena agroindústria. Fortaleza: Fundação Konrad Adenauer, Instituto de Assessoria para o Desenvolvimento Humano, 2005. 
QUEIROZ, G. J. de F.; LUNAS, D. A. L.; FRIAS, Q. A. Análise de crédito do PRONAF no estado de Goiás no período de 100-2011. Revista Desenvolvimento Socioeconômico em Debate - RDSD, v. 1, n. 2, 2015.

RAMOS FILHO, E. S. Questão agrária atual: Sergipe como referência para um estudo confrontativo das políticas de reforma agrária e reforma agrária de mercado (2003-2006) 428f. Tese. Programa de Pós-graduação em Geografia da Faculdade de Ciências e Tecnologia. Universidade Estadual Paulista. Presidente Prudente, 2008.

RODRIGUES, V. P. A. As Novas/Velhas Estratégias do Capital Sob o Simulcrado das Políticas de Desenvolvimento para o Campo. In: XXIII ENGA - Encontro Nacional de Geografia Agrária, 2016, São Cristóvão. ANAIS XXIII ENGA, 2016.

ROMÃO, L. M. S.; PACÍFICO, S. M. R. Muito além de diz e lousa: análise do legítimo discursivo em torno da questão agrária. Revista NERA. Presidente Prudente. Ano 11, no 12. p. 98 - 107. jan-jun, 2008.

SAUER, S. Agricultura familiar versus agronegócio: a dinâmica sociopolítica do campo brasileiro. Texto para discussão. Embrapa informação tecnológica. Brasília, 2008.

SCHNEIDER, S.; CAZELLA, A. A.; MATTEI, L. Histórico, caracterização e dinâmica recente do Pronaf - Programa Nacional de Fortalecimento da Agricultura familiar. In: SCHNEIDER, S.; SILVA, M. K.; MARQUES, P. E. M. (Org.). Políticas públicas e participação social no Brasil rural. Porto Alegre: Ed. da UFRGS, 2004. p. 21-49.

SHANIN, T. Peasants and peasant societies. Harmondsworth, UK: Penguin Books, 1971.

SILVA, T. H. C. O Desenvolvimento como paradigma da questão agrária: o capitalismo agrário em discussão. XXV Congresso do CONPEDI - Curitiba. Direito Agrário e Ambiental. Florianópolis: CONPEDI, 2016. p. 236 a 256.

VEIGA, J. E. Muita fantasia sobre um único assunto. Folha de São Paulo. 2004. Disponível em: <http://www1.folha.uol.com.br/fsp/dinheiro/fi2801200408.htm>. Acesso em: 30 mar. 2018.

WOLF, E. Sociedades Camponesas. Rio de Janeiro: Zahar Editores, 1970.

WANDERLEY, M. N. B. O campesinato brasileiro: uma história de resistência. RESR, Piracicaba-SP, vol. 52, supl.1, p. 25-44, 2014.

WANDERLEY, M. N. B. Raízes históricas do campesinato brasileiro. Trabalho apresentado no XX Encontro Anual da ANPOCS. GT 17 - Processos sociais agrários. Caxambu-MG. Out. 1996.

WOORTMANN, E.; WOORTMAN, K. O trabalho da terra: a lógica e a simbólica da lavou camponesa. Brasília: Editora da UNB, 2997. 